\title{
Biotransformation and chemotaxis of 4-chloro-2-nitrophenol by Pseudomonas sp. JHN
}

\author{
Pankaj Kumar Arora* and Hanhong Bae*
}

\begin{abstract}
Pseudomonas sp. JHN decolourized and biotransformed 4-chloro-2-nitrophenol (4C2NP) in the presence of additional carbon source. The effect of the various concentrations of the 4C2NP was studied on the decolourization of 4C2NP by Pseudomonas sp. JHN. It was observed that strain JHN decolourized and biotransformed 4C2NP up to concentration of $0.6 \mathrm{mM}$. Gas chromatography and gas chromatography-mass spectrometry detected 5-chloro-2-methylbenzoxazole as a major metabolite of the co-metabolism of 4C2NP. Furthermore, strain JHN exhibits positive chemotaxis toward 4C2NP based on the drop plate and capillary assays. This is the first report of the chemotaxis toward 4C2NP by any bacterium.
\end{abstract}

Keywords: 5-Chloro-2-methylbenzoxazole, Biotransformation, Chemotaxis, 4-Chloro-2-nitrophenol, Pseudomonas sp.

\section{Introduction}

4-Chloro-2-nitrophenol (4C2NP) is an anthropogenic toxic compound that has been detected in various contaminated sites over the world [1]. Several physicochemical methods including advanced oxidation processes have been used to decontaminate wastewater containing 4C2NP [2]. These physicochemical methods are not so much effective as compare to bacterial bioremediation which has been identified as an emerging approach for degradation of various xenobiotic compounds [2].

Despite the fact that $4 \mathrm{C} 2 \mathrm{NP}$ is a recalcitrant molecule to bacterial attack due to presence of two electron withdrawing groups, a few reports have been published dealing with the bacterial degradation of 4C2NP [3-6]. Arora et al. [1] studied complete mineralization of the 4C2NP by Exiguobacterium sp. PMA that degraded it with stoichiometric release of chloride and ammonium ions. The degradation pathway involves the reduction of the 4C2NP into 4-chloro-2-aminophenol that dehalogenated to aminophenol which was degraded further with release of ammonia. A genetically engineered bacterium, Pseudomonas sp. N31 mineralized 4C2NP with release of chloride and nitrite ions and formation of 4-chlorocatechol [3]. The biotransformation and detoxification of 4C2NP has been studied in two Bacillus species isolated from two

\footnotetext{
* Correspondence: arora484@gmail.com; hanhongbae@ynu.ac.kr

School of Biotechnology, Yeungnam University, Gyeongsan, Gyeongbuk 712-749, Republic of Korea
}

different ecological niches [4,5]. A marine bacterium, Bacillus sp. MW-1 and a soil bacterium, Bacillus subtilis RKJ 700 decolourized 4C2NP in the presence of additional carbon source. Both of the strains biotransformed 4C2NP into 5-chloro-2-methylbenzoxazole via formation of 4-chloro-2-aminophenol and 4-chloro-2acetaminophenol [4,5]. 4-Chloro-2-aminophenol and 4chloro-2-acetaminophenol were also identified as the metabolites in the degradation pathway of 4C2NP using the co-culture of two bacteria, Enterobacter cloacae and Alcaligenes sp. TK-2 [6]. In this communication, we describe the biotransformation and chemotaxis of 4C2NP by a previously isolated bacterium, Pseudomonas sp. JHN.

\section{Materials and methods Chemicals}

4C2NP was purchased from Aldrich (Milwaukee, Wis.). 5-chloro-2-methylbenzoxazole was purchased from Across Organics. All other chemicals were used of high purity grade.

\section{Bacteria and growth conditions}

Bacteria used in this study was Pseudomonas sp. JHN previously isolated from waste water collected from a chemically-contaminated area, India by an enrichment method [7]. This bacterium utilized 4-chloro-3-nitrophenol as the sole carbon and energy source [7]. However, this strain was unable to utilize $4 \mathrm{C} 2 \mathrm{NP}$ as the sole source 
of carbon and energy but decolourized and transformed $4 \mathrm{C} 2 \mathrm{NP}$ in the presence of additional carbon source. In this communication, we have monitored the ability of strain $\mathrm{JHN}$ to decolourize and bio-transformed $4 \mathrm{C} 2 \mathrm{NP}$ in the presence of additional carbon source (i.e., glucose). This strain was grown on minimal media containing 4C2NP and glucose under shaking conditions $(200 \mathrm{rpm})$ at $30^{\circ} \mathrm{C}$. The composition of minimal media was exactly same as described previously $[4,5,7]$.

\section{Growth and decolourization studies}

To monitor the effects of different concentrations of $4 \mathrm{C} 2 \mathrm{NP}$ on the growth of strain JHN and decolourization of $4 \mathrm{C} 2 \mathrm{NP}$, strain JHN was grown on $500 \mathrm{ml}$ Erlenmeyer flask containing $200 \mathrm{ml}$ minimal media, $10 \mathrm{mM}$ glucose and appropriate concentration of 4C2NP (0.2 mM/0.4 mM/0.6 mM/ $0.8 \mathrm{mM})$. Samples were collected at regular intervals and the bacteria growth was monitored by taking absorbance at $600 \mathrm{~nm}[4,5]$.

For decolourization studies, the samples collected at regular intervals were centrifuged. The decolourization was monitored by the measuring the absorbance of supernatant at $420 \mathrm{~nm}$ using U.V-Visible spectrophotometer [5]. The percentage decolourization was calculated according to the formula as described previously [5]:

$\%$ Decolourization $=($ Initial Absorbance -Absorbance after time $\mathrm{t})$ $\times 100 /$ Initial Absorbance.

\section{Identification of metabolites}

Strain JHN was grown in $500 \mathrm{ml}$ Erlenmeyer flask containing $200 \mathrm{ml}$ minimal media, $0.6 \mathrm{mM} 4 \mathrm{C} 2 \mathrm{NP}$ and
$10 \mathrm{mM}$ glucose. Samples $(50 \mathrm{ml})$ were collected at regular intervals $(0,12$ and $16 \mathrm{~h})$ and centrifuged at $8000 \mathrm{~g}$ for $15 \mathrm{~min}$. The samples were extracted with ethyl acetate and analyzed by the gas-chromatography and the gas chromatography-mass spectrometry (GC-MS) by methods as described previously [7].

\section{Detection of ammonia, nitrite and chloride}

The ammonium, nitrite and chloride ions were analyzed by the methods as described previously [4,5,7-9].

\section{Chemotaxis towards 4C2NP}

The chemotactic response of Pseudomonas sp. JHN toward 4C2NP was investigated qualitatively with drop plate assay and quantitatively with capillary assay as described by Pandey et al. [10]. In drop plate assay, bacterial cells were grown in minimal media containing $0.6 \mathrm{mM} 4 \mathrm{C} 2 \mathrm{NP}$ and $10 \mathrm{mM}$ glucose. The cells were harvested at mid-log phase (OD600 0.35) by centrifugation at $10000 \mathrm{rpm}$ for $15 \mathrm{~min}$. Harvested cells were washed twice with phosphate buffered saline, resuspended in minimal medium containing $0.3 \%$ bacto agar and poured into $96 \mathrm{~mm}$ petri plate [10]. Few crystals of 4C2NP were placed in the center of petri-plate and petri-plate was incubated at $30^{\circ} \mathrm{C}$ [10]. The chemotactic response was observed after $6 \mathrm{~h}$ of incubation. A positive response was indicated by the formation of concentric chemotaxis rings, due to bacterial cell accumulation encircling the crystals $[7,10]$. Capillary assay was performed as described previously [7]. The optimum concentration of 4C2NP for capillary assay was determined by performing assays at various 4C2NP concentrations (from 50-550 $\mu \mathrm{M}$ in $50 \mu \mathrm{M}$ increments). In capillary assay, a $10 \mu \mathrm{l}$ glass capillary was filled

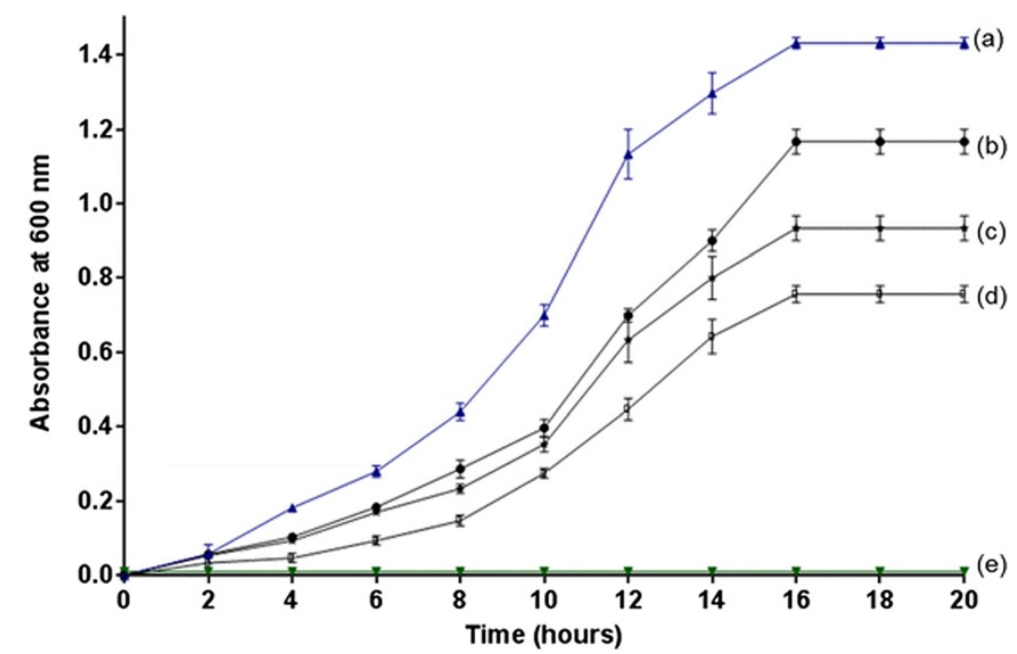

Figure 1 Growth curves of Pseudomonas sp. JHN in different conditions. Growth of Pseudomonas sp. JHN in (a) $10 \mathrm{mM}$ glucose (as positive control), (b) $10 \mathrm{mM}$ glucose and $0.2 \mathrm{mM} 4 \mathrm{C} 2 \mathrm{NP}$, (c) $10 \mathrm{mM}$ glucose and $0.4 \mathrm{mM} 4 \mathrm{C} 2 \mathrm{NP}$, (d) $10 \mathrm{mM}$ glucose and $0.6 \mathrm{mM} 4 \mathrm{C} 2 \mathrm{NP}$ and (e) $10 \mathrm{mM}$ glucose and $0.8 \mathrm{mM} 4 \mathrm{C} 2 \mathrm{NP}$. 
with a solution of desired concentration of $4 \mathrm{C} 2 \mathrm{NP}$ (in chemotaxis buffer consisting of $100 \mathrm{mM}$ potassium phosphate ( $\mathrm{pH} 7.0)$ and $20 \mu \mathrm{M}$ EDTA) and then inserted into a glass slide containing a suspension $\left(10^{13} \mathrm{cells} / \mathrm{ml}\right)$ of cells of strain $\mathrm{JHN}$, and incubated at $30^{\circ} \mathrm{C}$ for $30 \mathrm{~min}[7,10]$. The contents of the capillary tubes were then serially diluted and plated onto nutrient agar. Colony forming units (CFUs) were counted after $48 \mathrm{~h}$ incubation at $30^{\circ} \mathrm{C}$. The strength chemotactic response was expressed in terms of the chemotaxis index, which is the ratio of the number of CFUs produced from the capillary containing the $4 \mathrm{C} 2 \mathrm{NP}$ to CFUs produced from a control capillary (i.e. chemotaxis buffer without any chemotactic compound) $[7,10]$. Aspartate was used as the positive control.

\section{Results and discussion}

A 4-chloro-3-nitrophenol-mineralizaing bacterium, Pseudomonas sp. JHN previously isolated from waste water collected from a chemically-contaminated area, India decolourized and biotransformed a yellow-orange coloured compound $4 \mathrm{C} 2 \mathrm{NP}$ in the presence of glucose as the additional carbon source. We have monitored the effect of different concentrations of $4 \mathrm{C} 2 \mathrm{NP}$ on the growth of Pseudomonas sp. JHN. Strain JHN was able to grow on $4 \mathrm{C} 2 \mathrm{NP}$ up to concentration of $0.6 \mathrm{mM}$ in the presence of $10 \mathrm{mM}$ glucose. The growth of the cells of strain JHN was higher at the lower concentrations of 4C2NP as compared to higher concentrations (Figure 1). No bacterial growth was observed when the concentration of $4 \mathrm{C} 2 \mathrm{NP}$ was $0.8 \mathrm{mM}$. This data suggests that the high concentrations of $4 \mathrm{C} 2 \mathrm{NP}$ are toxic to the cells of strain JHN and inhibits the bacterial growth.

We have also investigated the effect of different concentrations of $4 \mathrm{C} 2 \mathrm{NP}$ on decolourization by Pseuodomonas sp. JHN. Strain JHN decolourized 4C2NP up to a

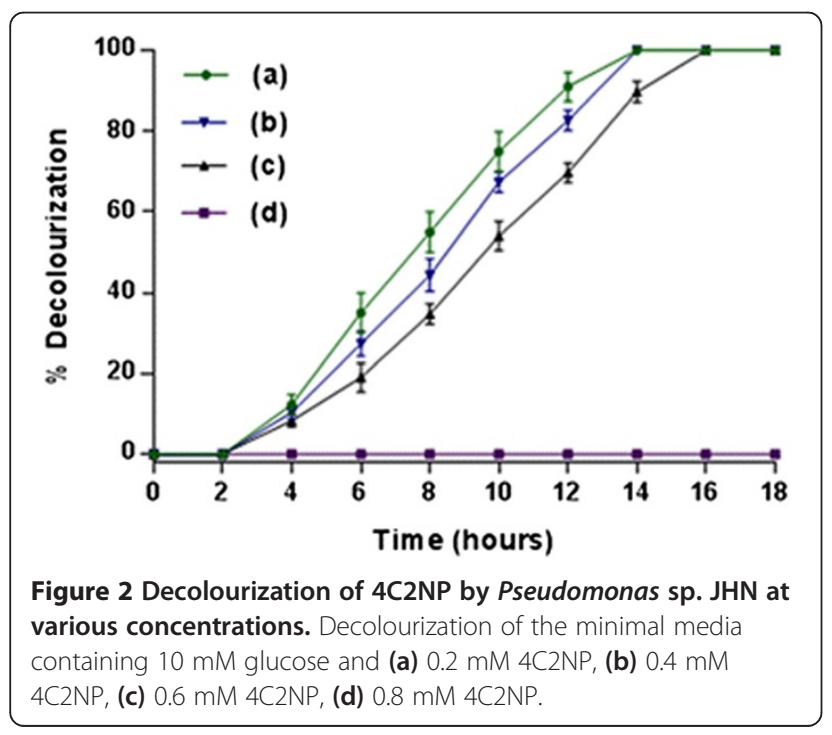

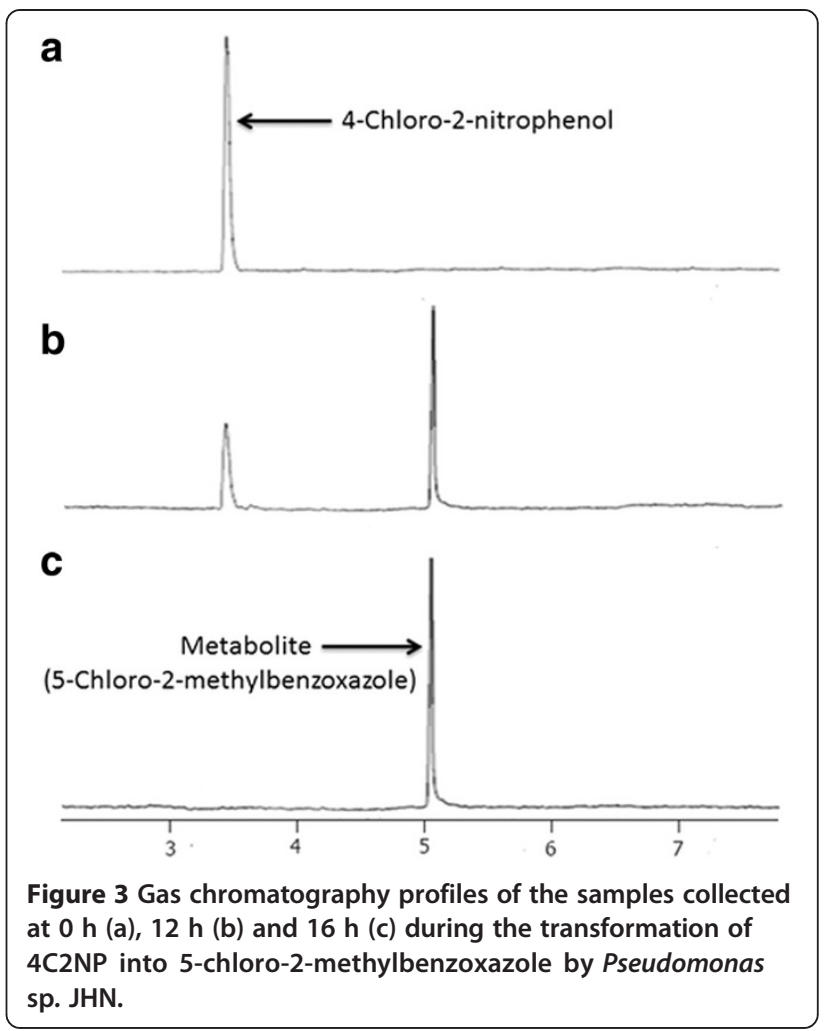

concentration of $0.6 \mathrm{mM}$. There was no decolourization at concentration above $0.6 \mathrm{mM}$ due to the inhibition of the growth of the cells of strain JHN. Strain JHN decolourized $0.6 \mathrm{mM}$ 4C2NP completely within 16 hours (Figure 2).

GC results confirmed the complete depletion of 4C2NP with appearance of single metabolite (Figure 3 ). In the

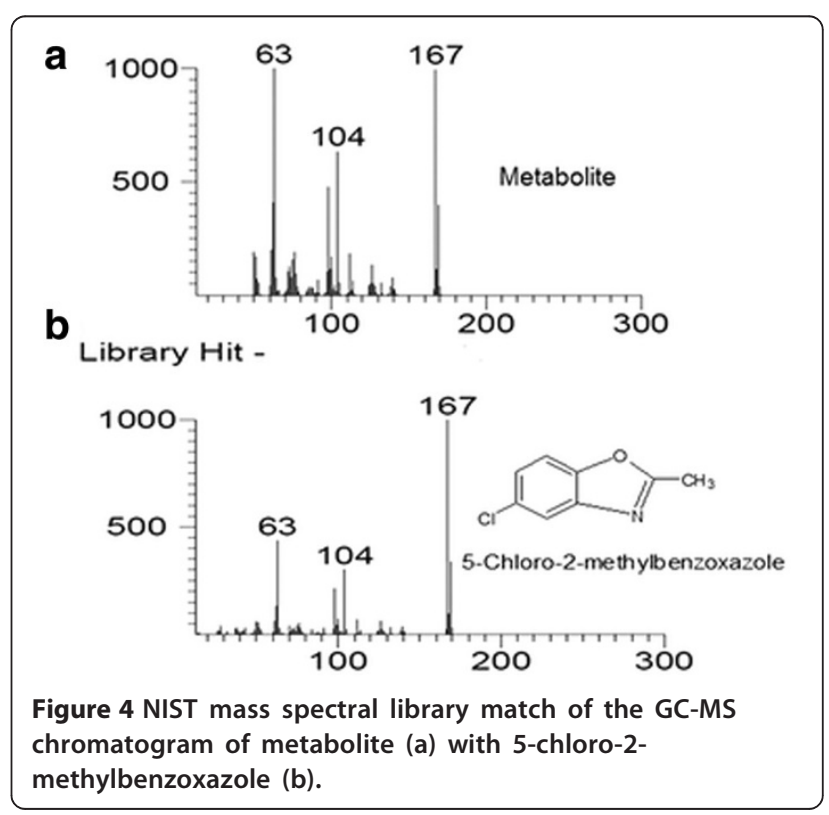




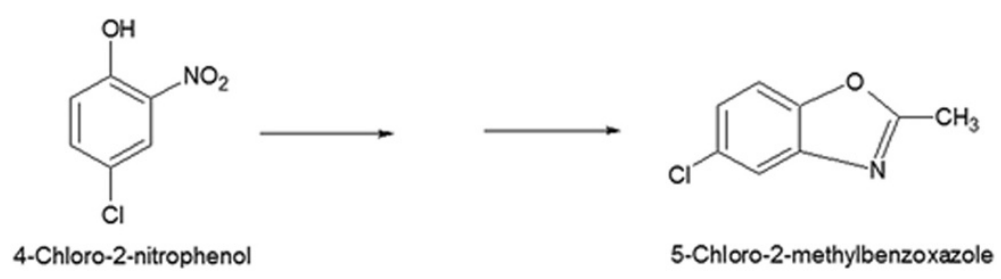

Figure 5 A graphic representation of transformation of 4-chloro-2-nitrophenol into 5-chloro-2-methylbenzoxazole.

sample of the $0 \mathrm{~h}$, only $4 \mathrm{C} 2 \mathrm{NP}$ was detected. In the sample of $12 \mathrm{~h}$, one peak of metabolite was appeared with a peak of parent compound. In the $16 \mathrm{~h}$, the peak of $4 \mathrm{C} 2 \mathrm{NP}$ was completely disappeared whereas the peak of metabolite was present. This data suggests that $4 \mathrm{C} 2 \mathrm{NP}$ was completely transformed to metabolite. To identify the metabolite, GC-MS was carried out. The mass fragment of the metabolite that was observed at $167 \mathrm{~m} / \mathrm{z}$ was subjected to the library search. NIST mass spectral library match showed that mass fragment of metabolite was exactly matched with to that of the 5-chloro-2-methylbenzoxazole (Figure 4). On the basis of the GC-MS, the transformation product was identified as 5-chloro-2-methylbenzoxazole. Previous studies have also been showed the formation of 5-chloro-2-methylbenzoxazole from 4C2NP by two Bacillus species $[4,5]$. The mechanism of formation of 5-chloro-2-methylbenzoxazole has also been studied in Bacillus sp. MW-1 and Bacillus subtilis RKJ 700. Both of the Bacillus spp. initially reduced to 4C2NP into 4-chloro2-aminophenol that was further acetylated to 4-chloro2-acetaminophenol [4,5]. 4-Chloro-2-acetaminophenol produced 5-chloro-2-methylbenzoxazole after cyclation. In the case of Pseudomonas sp. JHN, we could not detected 4-chloro-2-aminophenol and 4-chloro-2acetaminophenol as biotransformation product due to the rapid transformation of 4C2NP to 5-chloro-2methylbenzoxazole (Figure 5).
Several bacteria degraded 4C2NP via different mechanisms without formation of 5-chloro-2-methylbenzoxazole $[1,3,6]$. Exiguobacterium sp. PMA initially reduced 4C2NP to 4-chloro-2-aminophenol that further converted to 2-aminophenol which was further degraded via ring cleavage [1]. A genetically engineered bacterium, Pseudomonas sp. N31 degraded 4C2NP via the formation of 4-chlorocatechol [3]. The combination of Enterobacter cloacae and Alcaligenes sp. TK-2 degraded $4 \mathrm{C} 2 \mathrm{NP}$ via formation of 4-chloro-2-aminophenol and 4-chloro-2acetaminophenol [6]. In case of Pseudomonas sp. JHN, 5chloro-2-methylbenzoxazole was formed which is more complex compound than 4C2NP. Further degradation of 5-chloro-2-methylbenzoxazole seems to be a challenging step due to its complex structure.

Several bacteria released chloride, nitrite and ammonium ions due to degradation of 4 C2NP $[1,3,6]$. A genetically engineered bacterium, Pseudomonas sp. N31 mineralized 4C2NP with release of chloride and nitrite ions [3]. A co-culture of two bacterium, Enterobacter cloacae and Alcaligenes sp.TK-2 degraded 4C2NP with release of chloride and ammonium ions [6]. Another bacterium, Exiguobacterium sp. PMA degraded 4C2NP with release of ammonium and chloride ions [1]. In the case of Pseudomonas sp. JHN, we have not detected chloride, ammonium and nitrite ions during the transformation of $4 \mathrm{C} 2 \mathrm{NP}$. This data suggests that the
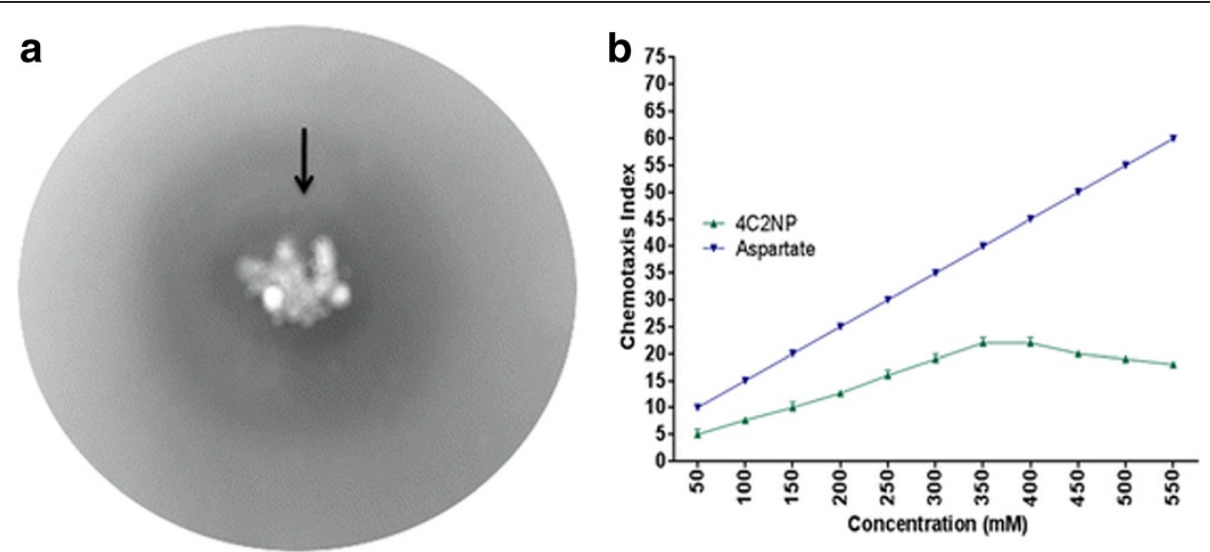

Figure 6 Chemotaxis towards 4C2NP. (a) Drop plate assay showing the bacterial ring around the crystals of 4C2NP. (b) Capillary assay showing the different chemotaxis index value toward different concentrations of 4C2NP. Aspartate was used as a positive control. 
transformation product should have chloro and nitrogen atoms.

Apart of biodegradation of 4C2NP, several reports have been published with degradation of $4 \mathrm{C} 2 \mathrm{NP}$ by physicochemical methods [11-13]. Mehrizad et al. [11] used single-walled and multi-walled carbon nanotubes for removal of 4C2NP from aqueous solutions through absorption. Gharbani et al. [12] studied the 4C2NP degradation in the pharmaceutical industrial wastewater by ozonation and identified chlorophenol as degradation product. Adami and Fakhri [13] studied the removal of 4C2NP from aqueous solutions using zero valent iron nanoparticles (nZVI) and Pd-doped zero valent iron nanoparticles (Pd-nZVI). These physicochemical methods are not as effective as bacterial degradation because they are not cost effective [2].

We have also monitored the chemotactic behavior of Pseudomonas sp. JHN toward 4C2NP using drop plate assay and capillary assay. Drop plate assay showed the formation of the bacterial ring around the crystals of 4C2NP after the incubation of $6 \mathrm{~h}$ (Figure 6a). In capillary assay, it was observed that Pseudomonas sp. JHN was chemotactic toward $4 \mathrm{C} 2 \mathrm{NP}$ at an optimum concentration of $350 \mu \mathrm{M}$ with a chemotaxis index of 22 . Figure $6 \mathrm{~b}$ show that the chemotaxis index value gradually increased with increased the concentration of $4 \mathrm{C} 2 \mathrm{NP}$ up to optimal concentration $(350 \mu \mathrm{M})$. After reaching the optimum concentration, there is no significant change in chemotaxis index value for $4 \mathrm{C} 2 \mathrm{NP}$. To the best of our knowledge, this is the first report of bacterial chemotaxis toward 4C2NP.

Pseudomonas sp. JHN also showed chemotaxis toward 4-chloro-3-nitrophenol and mineralized it via formation of chlororesorcinol [7]. Pseudomonas sp. JHN showed chemotaxis toward those compounds which it can metabolize or cometabolize. Strain JHN did not show chemotaxis those compounds which are not degraded or transformed by strain JHN. This kind of chemotaxis is known as metabolism-dependent chemotaxis [14]. Another type of chemotaxis is metabolism-independent chemotaxis which is independent of metabolism of chemo-attractants [14]. Both metabolism-independent and metabolism-dependent type chemotaxis have been studied in bacteria [14]. Pseudomonas sp. strain WBC-3 and P. putida PRS2000 exhibited metabolismindependent chemotaxis towards various aromatic compounds [15-18]. Another bacterium, Burkholderia sp. SJ98 [19] has been characterized for its metabolism-dependent chemotactic behavior toward various nitroaromatic compounds. Pandey et al. [10] reported that strain SJ98 also exhibited chemotactic response toward chloronitrophenols including 2-chloro-4-nitrophenol and 2-chloro-3nitrophenol [10]. However, strain SJ98 neither utilizes $4 \mathrm{C} 2 \mathrm{NP}$ nor shows chemotactic behavior toward $4 \mathrm{C} 2 \mathrm{NP}$
[10]. We have shown chemotactic behavior of Pseudomonas sp. JHN toward 4C2NP in our current report. It has been proved that chemotaxis enhanced bioavailability of chemicals to the bacteria that is helpful for bioremediation processes [20].

\section{Conclusion}

Pseudomonas sp. JHN transformed 4C2NP into 5-chloro2-methylbenzoxazole and showed chemotaxis toward $4 \mathrm{C} 2 \mathrm{NP}$. To the best of our knowledge, this is the first report of bacterial chemotaxis toward $4 \mathrm{C} 2 \mathrm{NP}$.

\section{Competing interests}

The authors declare that they have no competing interests.

\section{Authors' contributions}

PKA designed and performed the experimental works. PKA prepared the manuscript and $\mathrm{HB}$ revised the manuscript. $\mathrm{HB}$ provides all chemicals and reagents for this study. PKA and $\mathrm{HB}$ analyzed the data. Both authors read and approved the final manuscript.

\section{Acknowledgement}

This research was supported by the Yeungnam University Research Grant in 213A380154.

Received: 2 June 2014 Accepted: 23 July 2014

Published: 12 August 2014

\section{References}

1. Arora PK, Sharma A, Mehta R, Damodara B, Srivastava A, Singh VP: Metabolism of 4-chloro-2-nitrophenol in a Gram-positive bacterium, Exiguobacterium sp. PMA. Microbial Cell Factories 2012, 11:150.

2. Arora PK, Sasikala C, Ramana VK: Degradation of chlorinated nitroaromatic compounds. Appl Microbiol Biotechnol 2012, 93:2265-2277.

3. Bruhn C, Bayly RC, Knackmus HJ: The in vivo construction of 4-chloro-2nitrophenol assimilatory bacteria. Arch Microbiol 1988, 150:171-177.

4. Arora PK, Jain RK: Biotransformation of 4-chloro-2-nitrophenol into 5-chloro-2. methylbenzoxazole by a marine Bacillus sp. strain MW-1. Biodegradation 2012, 23:325-331.

5. Arora PK: Decolourization of 4-chloro-2-nitrophenol by a soil bacterium, Bacillus subtilis RKJ 700. PLoS One 2012, 7:e52012.

6. Beunink J, Rehm HJ: Coupled reductive and oxidative degradation of 4-chloro-2-nitrophenol by a co-immobilized mixed culture system. Appl Microbiol Biotechnol 1990, 34:108-115.

7. Arora PK, Srivastava A, Singh VP: Degradation of 4-chloro-3-nitrophenol via a novel intermediate, 4-chlororesorcinol by Pseudomonas sp. JHN. Sci Rep 2014, 4:4475.

8. Arora PK, Jain RK: Pathway for degradation of 2-chloro-4-nitrophenol by Arthrobacter sp. SJCon. Curr Microbiol 2011, 63:568-573.

9. Arora PK, Jain RK: Metabolism of 2-chloro-4-nitrophenol in a Gram negative bacterium, Burkholderia sp. RKJ 800. PLoS One 2012, 7:e38676.

10. Pandey J, Sharma NK, Khan F, Ghosh A, Oakeshott JG, Jain RK, Pandey G: Chemotaxis of Burkholderia sp. strain SJ98 towards chloronitroaromatic compounds that it can metabolise. BMC Microbiol 2012, 12:19.

11. Mehrizad A, Aghaie M, Gharbani P, Dastmalchi S, Monajjemi M, Zare K: Comparison of 4-chloro-2-nitrophenol adsorption on single-walled and multi-walled carbon nanotubes. Iran J Environ Health Sci Eng 2012, 9:5.

12. Gharbani P, Khosravi M, Tabatabaii SM, Zare K, Dastmalchi S, Mehrizad A: Degradation of trace aqueous 4-chloro-2-nitrophenol occurring in pharmaceutical industrial wastewater by ozone. Int J Environ Sci Technol 2010, 7:377-384.

13. Adami S, Fakhri A: Adsorption of 4-chloro-2-nitrophenol by zero valent iron nanoparticles and $\mathrm{Pd}$-doped zero valent iron nanoparticles surfaces: isotherm, kinetic and mechanism modeling. J Phys Chem Biophys 2013, 3:115

14. Pandey G, Jain RK: Bacterial chemotaxis toward environmental pollutants: role in bioremediation. Appl Environ Microbiol 2002, 68:5789-5795. 
15. Zhang J, Xin Y, Liu H, Wang S, Zhou N: Metabolism-independent chemotaxis of Pseudomonas sp. strain WBC-3 toward aromatic compounds. J Environ Sci 2010, 20:1238-1242.

16. Parales RE: Nitrobenzoates and aminobenzoates are chemoattractants for Pseudomonas strains. Appl Environ Microbiol 2004, 70:285-292.

17. Harwood CS, Ornston LN: TOL plasmid can prevent induction of chemotactic responses to aromatic acids.J Bacterio/ 1984, 160:797-800.

18. Harwood CS, Parales RE, Dispensa M: Chemotaxis of Pseudomonas putida toward chlorinated benzoates. Appl Environ Microbiol 1990, 56:1501-1503.

19. Samanta SK, Bhushan B, Chauhan A, Jain RK: Chemotaxis of a Ralstonia sp. SJ98 toward different nitroaromatic compounds and their degradation. Biochem BiophysRes Commun 2000, 269:117-123.

20. Arora PK, Srivastava A, Singh VP: Bacterial degradation of nitrophenols and their derivatives. J Hazard Mater 2014, 266:42-59.

doi:10.1186/s12934-014-0110-7

Cite this article as: Arora and Bae: Biotransformation and chemotaxis of 4-chloro-2-nitrophenol by Pseudomonas sp. JHN. Microbial Cell Factories 2014 13:110

\section{Submit your next manuscript to BioMed Central and take full advantage of:}

- Convenient online submission

- Thorough peer review

- No space constraints or color figure charges

- Immediate publication on acceptance

- Inclusion in PubMed, CAS, Scopus and Google Scholar

- Research which is freely available for redistribution 